\title{
La Iglesia y la universalidad de la salvación en el cristianismo
}

El objeto del presente trabajo es una reflexión acerca de la universalidad de la salvación en el cristianismo. Se trata de describir cómo se comprende que Cristo sea el único mediador y que su salvación sea universal, y la relación que adquiere la humanidad toda con el Resucitado. Este tema, sin embargo, desde un punto de vista católico, no puede ser separado de otra verdad fundamental: la necesidad de la Iglesia para la salvación (cf. LG 14 y 48). Y este último argumento significa reflexionar sobre la Iglesia como sacramento, esto es, sobre "la cuestión de la mediación institucional de la salvación. En otras palabras, la cuestión de saber si y en qué medida la Iglesia no solamente es comunidad, lugar y espacio de salvación, sino también, en nombre de Jesucristo, sea causa instrumental, mediación de salvación" (1). El tema, entonces, ha de ser abordado en cuatro grandes aspectos: Qué significa salvación; quién trae la salvación; cómo esta puede ser universal; y qué papel juega la Iglesia en esta salvación universal, en cuanto sacramento universal de salvación.

\section{EL CONCEPTO DE SALVACIÓN}

Comencemos explicando qué significa salvación. Podemos decir que "la salvación es la cuestión humana primordial" (2). Esta noción habla del ser y del sentido último de lo humano, intenta describir conceptos como integridad, trascendencia, plenitud, futuro mejor, afirmación de la propia existencia, dignidad, presente sano, etc. (3).

Ahora bien, la idea de salvación supone que en el hombre existe la necesidad, aunque sea en forma implícita, de una tal salvación. Y así ocurre efectivamente. Es

(1) W. KASPER, Unité ecclésiale et communion ecclésiale dans une perspective catholique: Revue des sciences religieuses 75 (2001) 6-22, aquí pág. 8. Continúa este autor: "La respuesta a esta cuestión nos lleva a la estructura fundamental de la Iglesia en tanto que signo e instrumento de salvación. Según un buen número de autores, en esta cuestión reside una, si no la diferencia fundamental (con la reforma)". ibíd.

(2) O. GonZÁlez de CARDEdAl, Cristología (Madrid 2001), 496.

(3) Cf. O. GonzÁlez de CARdedal, Cristología..., 496. 
evidente que la experiencia humana universal se encuentra con la necesidad de superar ciertas cosas negativas que padece, además busca realizar ciertas aspiraciones profundas de felicidad y plenitud que experimenta, y se siente también inclinada "a saciar el anhelo de lo absolutamente sano y santo, que no es la prolongación de lo que nosotros somos, sino de algo totalmente Otro, en el encuentro con el cual somos transformados" (4): ese es Dios. Lograr esas tres cosas es lo que entendemos por salvación.

Sin embargo, la realización de esto supone la "transformación de nuestra realidad actual, el tránsito a otra forma de vida" (5). Y "el hombre sabe que todo eso no lo puede alcanzar por sí mismo, que no se puede consumar por su esfuerzo" (6). De ahí que la salvación, por ahora, sea realidad alcanzada solo en forma fragmentaria y objeto de esperanza futura. Así entendida, la salvación solo puede venir de Dios que reconoce como valiosa y capaz de transformación la vida del hombre; que libera al hombre de su culpa moral; y que acoge sanando y santificando al hombre ofreciéndole un futuro de plenitud y de amor.

Esta salvación ha sido explicitada a lo largo de la historia con diversos conceptos, según el aspecto que más se haya querido destacar: divinización, justificación, sacrificio, expiación, redención, satisfacción, sustitución, reconciliación, liberación, etc. En nuestro contexto actual, la salvación puede ser bien comprendida con el concepto bíblico de comunión (7). En efecto, ya en el relato de la creación encontramos a Dios que dice: "no es bueno que el hombre esté solo" (Gén 2,18 ) y por eso le hace una ayuda adecuada, de los huesos de sus huesos y de la carne de su carne (Gén 2,23), es decir, de su igual condición y dignidad. Y da a nuestros primeros padres el mandato de ser fecundos y multiplicarse (Gén 1,28). Así, Dios, al haber formado al género humano a su imagen y semejanza (Gén 1,26) y con su Espíritu de vida (Gén 2,7), lo ha creado como una familia (8) llamada a participar de la vida divina (LG 2). Y tras la caída en el pecado, no lo ha abandonado a su miseria, impotencia y ruptura de la comunión. Por el contrario, en Cristo Redentor ha devuelto a la humanidad a la comunión con Dios y entre sí. Pero esto Dios lo llevó a cabo santificando y salvando a los hombres "no individualmente y aislados, sin conexión entre sí" (LG 9), sino que constituyéndolos como "un pueblo para que le conociera de verdad y le sirviera con una vida santa"

(4) O. GonzÁlez de CARdedal, Cristología..., 497.

(5) O. GonzÁlez de CARDEDAl, Cristología..., 497.

(6) O. GONZÁlez de CARdedAl, Cristología..., 497.

(7) En el NT la palabra comunión significa, por una parte, participación en el Dios Trino. En el Padre (1 Jn 1,3), en el Hijo (1 Jn 1,3; 1 Cor 1,9) o en el Espíritu Santo (2 Cor 13,13). Esa co-participación en Dios nace de la participación en el cuerpo eucarístico de Cristo (1 Cor 10,16-17). Significa también la solidaridad de la Iglesia consigo misma, expresada en la colecta hecha en beneficio de las comunidades que pasan necesidad (2 Cor 9,13; Rom 15,26). Siendo miembros de un mismo cuerpo todos son solidarios con las necesidades de los otros miembros del mismo cuerpo. Y significa también la misma asamblea eclesial (1 Jn 1,3.6-7; Gál 2,9-10; Hech 2,42). La comunión es algo característico de la Iglesia entendida como Cuerpo de Cristo y germen del Reino. Cf. J. HAMER, La Iglesia es una comunión (Barcelona 1965), 153-158. Cf. También B. J. HiLberAtH, Zwischen Vision und Wirklichkeit. Fragen nach dem Weg der Kirche (Würzburg 1999), 52-64.

(8) En cuanto tiene un origen común. De allí todo el drama de la muerte de Abel por manos de su hermano Caín (Gén 4,1-16). El mensaje es claro: "Todo hombre es mi hermano, hueso de mis huesos y carne de mi carne". 
(LG 9) y haciendo de la humanidad una familia de Dios (Ef 2,19; LG 6). Por eso, bien podemos definir la salvación como la unión íntima de los hombres con Dios y la unidad de todo el género humano entre sí (LG 1), con lo que ello significa de liberación de todo mal y plenitud de todo anhelo y posibilidad del hombre.

\section{EL ÚNICO MEDIADOR: CRISTO, EL HIJO DE DIOS HECHO CARNE}

Ahora bien, si la salvación solo puede venir de Dios, el cristianismo ve realizado esto en la persona de Jesús de Nazaret, Logos de Dios hecho carne, muerto y resucitado por nosotros. En efecto, esta es la afirmación básica de nuestra fe: Cristo es el único Salvador, el mediador entre Dios y los hombres, él mismo Dios y hombre. Leemos en 1 Tim 2,5-6: "Porque hay un solo Dios, y también un solo mediador entre Dios y los hombres, Cristo Jesús, hombre también, que se entregó a sí mismo como rescate por todos". Entonces frente a la radical necesidad de salvación-comunión que posee todo hombre, la cual solo puede venir de Dios, encontramos que esta se realiza precisamente en Cristo como Dios mismo en medio de nosotros.

Es esa y no otra la pretensión inaudita de Jesús acerca de que "en su persona y en su obra, Dios ha hecho su entrada escatológica en la historia" (9), pretensión que fundamenta "el carácter de exigencia de su anuncio: la urgencia de la decisión a favor o en contra de él" (10) (cf. Lc 14,26; Jn 14,6). "La fe cristiana, a su vez, ya desde sus orígenes, se mostró inseparable de una pretensión análoga de carácter absoluto, vinculada precisamente a la convicción de que su objeto, el Señor crucificado y resucitado, es de forma definitiva y absoluta la norma y la medida de la historia" (11). Jesús es entonces -en palabras de Rahner- el Salvador absoluto. Es decir, es "aquella personalidad histórica que, apareciendo en el espacio y el tiempo, significa el principio de la autocomunicación absoluta de Dios que llega a su fin, aquel principio que señala la autocomunicación para todos como algo que acontece irrevocablemente y como inaugurada de manera victoriosa" (12). Sin embargo, "no puede ser simplemente Dios como el actor mismo que obra en el mundo; debe ser un trozo del cosmos, un momento de su historia y, además, en su punto cumbre" (13).

(9) B. FORTE, La Iglesia de la Trinidad. Ensayo sobre el misterio de la Iglesia comunión y misión (Salamanca 1996), 109.

(10) B. ForTe, La Iglesia..., 108.

(11) B. ForTe, La Iglesia..., 109.

(12) K. RAHnER, Curso fundamental sobre la fe. Introducción al concepto de cristianismo (Barcelona 1989), 233. Continúa el autor: "No decimos que la comunicación de Dios mismo al mundo en su objetividad espiritual debe comenzar temporalmente con ella. Puede comenzar ya antes del salvador, e incluso ser coexistente con toda la historia espiritual de la humanidad y del mundo... Aquí se llama salvador: a) aquella subjetividad histórica en la que el suceso de la comunicación absoluta de Dios mismo al mundo espiritual está ahí como irrevocable en conjunto; b) aquel suceso en el que esta autocomunicación divina puede conocerse inequívocamente como irrevocable; y c) aquel suceso en el que la comunicación de Dios mismo llega a su punto cimero, en tanto este debe pensarse como un momento en la historia entera de la humanidad y en cuanto no ha de identificarse simplemente con la totalidad del mundo espiritual que se halla bajo la autocomunicación divina" (Ibíd.).

(13) K. RAHNER, Curso fundamental..., 235. 
Significa tanto la autocomunicación misma, como su aceptación. Por eso el dogma cristológico afirma que "Jesús es verdaderamente hombre, verdaderamente un trozo de tierra... un momento en la historia natural humana, pues 'nació de una mujer' (Gál 4,4)" (14). Es el absolutum que ha devenido concretissimum.

Sin embargo, este carácter absoluto del cristianismo no llega a ser una práctica totalitaria ni se transforma en una ideología, precisamente por la índole propia de esta automanifestación de Dios: está marcada por la encarnación y por la cruz. En efecto, la revelación es siempre y a la vez "manifestación de la presencia y ocultamiento de la ausencia" (15). Esto significa que "solo se acoge de veras la palabra cuando se la escucha superándola, o sea, cuando se la obedece escuchando lo que está más allá, por detrás y más hondo que ella. Escuchar la palabra de Cristo significa entonces escuchar lo que está más allá de esa palabra, el silencio del origen de donde proviene: Cristo palabra del Padre remite a la profundidad de lo escondido... En una palabra, la revelación se presenta como un 'concretissimum', en donde llega a manifestarse la inefable profundidad de Dios, sin resolverse en ello" (16). Todo esto quiere decir que la singularidad de Cristo y de su anuncio es que apela siempre a la libertad. "Delante de él está siempre abierta la posibilidad del rechazo, exigiéndose por tanto a todos un absoluto respeto. Cristo no puede ser impuesto a nadie; solo puede ser propuesto. Él es la invitación radical a la audacia de la libertad, porque la ley fundamental de la 're-velatio' es ese escondimiento que apela a la obediencia de la fe... Todo esto significa... que ante la singularidad de Cristo lo que sigue estando en manos del hombre es la decisión ante la buena nueva, cuando ha llegado hasta él de manera creíble a través de la memoria evangélica de la tradición cristiana viva" (17). Es una toma de posición consciente y libre, frente a un dato externo, que llega a través de una comunidad, que da testimonio de un acontecimiento que le ha cambiado su vida.

\section{EN CRISTO HA LLEGADO LA SALVACIÓN ESCATOLÓGICA, ES DE- CIR, DEFINITIVA Y UNIVERSAL}

Ahora bien, esta presencia de Cristo como mediador entre Dios y los hombres y como salvador absoluto, o sea, como Dios mismo presente en forma irrevocable y cimera, hace que su salvación sea escatológica, es decir, definitiva y universal. Esto significa, en primer lugar, que en Cristo Dios se ha comunicado a todos los hombres de manera definitiva. En su persona, en su anuncio, en sus acciones significativas, y sobre todo, en su muerte y resurrección, se encuentra ya anticipada la esperada comunión con Dios (18). Es decir, lo definitivo está realmente presente en la figura intrahistórica de Jesús, aunque no todavía en su esplendor consumado. Dios mismo ha salido al encuentro del hombre en la figura histórica de Cristo. En Él nos llama a la conver-

(14) K. RAHNER, Curso fundamental..., 235.

(15) B. ForTe, La Iglesia..., 112.

(16) B. FORTE, La Iglesia..., 112-113.

(17) B. ForTE, La Iglesia..., 113-114.

(18) Cf. M. KEHL, Escatología (Salamanca 1992), 220. 
sión. En él realiza su diálogo salvífico con nosotros. "En Cristo, en su persona y en su historia puede, por tanto, contemplarse la plenitud del don salvífico otorgado por el Padre" (19). Y esa salvación se hace presente en nosotros a través del Espíritu del resucitado. El Espíritu Santo es tanto "el contenido de todos los dones salvíficos, como la garantía de la última comunión con Dios" (20). Es el principio dinámico de una vida nueva, deiforme y prenda de esa filiación divina que nos regala Cristo. Es el don "que vive en nosotros, que nos cautiva y nos prepara para la última manifestación cara a cara con el Padre. La meta de la salvación de Dios y, por lo mismo, el efecto más universal de la redención lo constituye esta comunión con Dios, patente ya ahora en Cristo y en el Espíritu, pero a la que falta aún la plenitud escatológica" (21).

Pero significa igualmente que en Cristo, verdadero Dios y verdadero hombre, y en el Espíritu, don altísimo de Dios, la humanidad entera ha sido transformada. Pablo habla del "hombre nuevo" frente al "hombre viejo". Habla de reconciliación frente a la enemistad, de gracia frente a la maldición, de libertad frente a la esclavitud, de salvación frente a la condenación. Esta nueva realidad es la continuación en el hombre, en todos los hombres, del destino de Cristo (22). "Los cristianos representan, por principio, la esperanza de la humanidad y el cambio operado por Dios mismo" (23). Así se puede afirmar que la salvación realizada por Cristo tiene un carácter protológico, recapitulador, único y universal. Protológico, porque "Cristo está al comienzo de las cosas y es su principio de realidad" (24). "Todo fue creado por Él y para Él" (Col 1,16). "Solo nos entenderemos plenamente desde Él y solo nos plenificaremos con Él" (25). Recapitulador, porque Cristo recapitula todas las cosas en sí mismo y es el centro y la plenitud de la historia (Gál 4,4; Ef 1,10). En Él la humanidad entera es renovada, divinizada y llevada a su plenitud. Igualmente afirmamos que en ningún otro hay salvación, "porque no hay bajo el cielo otro nombre dado a los hombres por el que nosotros debamos salvarnos" (Hech 4,12). Dios se ha hecho presente personalmente en su Hijo y ya no debemos ni podemos esperar otra manifestación de Dios. Dios ya está aquí en medio de nosotros. Por la modalidad y pureza de la revelación en Cristo se da una garantía oficial de verdad y de gracia insuperables que la hacen ser la revelación por excelencia. "Con ello, el suceso de Cristo pasa a ser la única cesura realmente aprensible para nosotros en la historia general de la salvación y revelación" (26). Y esta mediación es absolutamente universal. Se extiende a todos los hombres de todos los tiempos. Dios "quiere que todos los hombres se salven y lleguen al conocimiento de la verdad" (1 Tim $2,4)$. Y todo esto a través de la figura histórica de Cristo encarnado, muerto y resucitado, como mediación visible y sensible de Dios. "En la carne alcanza Dios su credibilidad final para el hombre. Cristo es así el lugar de Dios para el hombre” (27).

(19) A. GRILlMEIER, El efecto de la acción salvífica de Dios en Cristo, en Mysterium Salutis, III, 848.

(20) A. GRILlMEIER, El efecto..., 848.

(21) A. GRILlMEIER, El efecto..., 848.

(22) Cf. A. GrillmeiER, El efecto..., 849.

(23) A. GRILLMEIER, El efecto..., 849.

(24) O. GonzÁlez de CARdedal, Cristología..., 549.

(25) O. GonzÁlez de CARdedal, Cristología..., 549.

(26) K. RAHNER, Curso fundamental..., 213.

(27) O. GonzÁlez de CARdedal, Cristología..., 550. 
Esta universalidad de la salvación es lo que se quiere expresar cuando se habla del reino de Dios inaugurado por Cristo. Entendemos por reino o reinado de Dios "ese acontecimiento realizado definitivamente en Cristo y prometido aún por él en virtud del cual la voluntad de justicia y paz de Dios -partiendo de Israel o del renovado pueblo de Dios, la Iglesia- crea en nuestra historia un espacio en sentido salvador y liberador" (28). El reino de Dios se encuentra entonces en la persona de Jesús. Y desde su persona se fundamenta toda "actualización del reino de Dios en la vida y el quehacer de todos aquellos que le siguen con la fuerza del Espíritu" (29). Estos son todos los hombres y mujeres "que enfocan su situación personal, sus opciones morales y su mundo social desde la voluntad de justicia y paz de Dios" (30), es decir, todos los hombres y mujeres "de buena voluntad, en cuyo corazón actúa la gracia de modo invisible... y a los que el Espíritu Santo ofrece la posibilidad de que, de un modo conocido solo por Dios, se asocien a este misterio pascual" (GS 22), que es la realización del reino de Dios. Entonces esta actualización intrahistórica del reino de Dios se puede producir tanto en una modalidad cristiana explícita, como también en una modalidad implícita. Todos han sido salvados por Cristo, a pesar que muchos todavía no lo sepan. Es la salvación objetiva de la humanidad a la cual todos pueden acceder por caminos conocidos solo por Dios.

Ahora bien, esta voluntad salvífica universal de Dios implica, por voluntad del mismo Dios, que los hombres reciban también "plena y conscientemente su obra salvadora" (AG 7). Efectivamente, el hombre en su condición de ser libre y consciente está llamado a acoger esa salvación también libre y conscientemente, como modo de obrar propio de su condición humana racional y libre. No podemos hablar de un acto verdaderamente humano que no sea, por eso mismo, consciente y libre. De allí que si bien la salvación universal traída por Cristo es acogida por cada hombre de forma consciente a partir de cada acto de bondad y verdad que realice a modo humano, con todo, por ser una acción movida por la gracia invisible de Cristo y la acción secreta del Espíritu Santo, igualmente cada acto está pidiendo una explicitación de esa relación con Dios que se establece con aquel mismo acto de bondad y verdad, para alcanzar así una acogida más plena y absolutamente definitiva del reino de Dios. Eso lo exige la naturaleza relacional propia de toda acción humana en orden a la salvación. La gracia es siempre relación con Dios, y no será plena mientras no sea totalmente explícita. Pero además, el hombre, al acoger explícitamente a Cristo y su obra salvadora, plenifica su propio ser y vida, ya que su vocación más íntima es realmente una sola, la divina (GS 22), es decir, la de "formar un único Pueblo de Dios, de unirse en un único cuerpo de Cristo y de coedificarse en un único templo del Espíritu Santo, lo cual, al reflejar la concordia fraterna, responde ciertamente al íntimo deseo de todos los hombres" (AG 7). En efecto, el designio de Dios es que todos los hombres puedan participar de su amor, manifestado a través de Cristo y realizado en el Espíritu Santo. Y esto para ser absolutamente pleno, necesita de ser también explicitado, no por una suerte de gnosticismo cristiano, sino porque el conocimiento y la libertad, acrecenta-

(28) M. KeHL, Escatología.., 219.

(29) M. KeHL, Escatología..., 220.

(30) M. KeHL, Escatología..., 220. 
rán siempre más el amor, por desarrollar más al propio hombre. A partir de aquí se entiende la necesidad y el deber de la misión en la Iglesia, ya que la "actividad misionera tiene una conexión íntima con la misma naturaleza humana y sus aspiraciones. Pues al manifestar a Cristo, la Iglesia revela a los hombres la auténtica verdad de su condición y de su vocación íntegra, siendo Cristo el principio y ejemplo de esa humanidad renovada, llena de amor fraterno, de sinceridad y de espíritu de paz, a la que todos aspiran" (AG 8) (31).

\section{LA UNIVERSALIDAD DE LA SALVACIÓN DE CRISTO Y SU RELACIÓN CON LA IGLESIA.}

Sin embargo, nuestra reflexión sobre la universalidad de la salvación traída por Cristo no termina aquí. En efecto, si la Palabra del Padre se ha revelado de manera definitiva y universal cuando ha devenido un concretissimum situado histórica y temporalmente, entonces lo histórico, temporal y concreto -lo finito-, ha llegado a ser lugar y medio de salvación. Ahora bien, este elemento concreto que es esencial a la revelación cristiana implica de por sí el recurso a la Iglesia. Efectivamente, la universalidad y definitividad de la salvación traída por la figura histórica y espacialmente delimitada de Jesucristo, encarnado, muerto y resucitado, como mediador visible y sensible entre Dios y los hombres, implica que esta misma salvación y este mismo mediador deben continuar presentes y actuantes en la historia humana presente y futura, también de un modo visible y sensible -espacial y temporalmente delimitado- hasta el fin de los tiempos. Así pues, a partir de la encarnación de Cristo, la salvación ha quedado marcada por este principio encarnatorio, de tal manera que siempre la salvación de Dios llega a través de mediaciones categoriales que explicitan la entrega trascendental de todo hombre a Dios. En ese contexto es entonces en donde se entiende auténticamente la realidad y la necesidad de la Iglesia y de su misión en todo el mundo: ella está constituida como presencia permanente de Cristo, para mediar en la entrega de todos los hombres a Dios a través de Cristo. Justamente, "la Iglesia es el acontecimiento de la actualización de Jesucristo y de su salvación definitiva para los hombres" (32). Esto "significa que la salvación ofrecida por Dios en Jesucristo y en el Espíritu Santo se nos da como tal en el signo finito y pecador de la Iglesia" (33). Todo lo que Dios realizó en Jesucristo para nosotros, se hace presente y actual hoy por la fuerza del Espíritu Santo en los actos centrales de la vida de la Iglesia (34). Cristo no se ha retirado del mundo después de su

(31) Cf. AG 7-8.

(32) M. KeHL, La Iglesia. Eclesiología católica (Salamanca 1996), 73.

(33) M. KeHL, La Iglesia..., 74.

(34) "El Concilio, que ha eludido un estudio de la Trinidad en sí misma, pero que la ha presentado en clave funcional, ha constituido a la Iglesia en objeto central de su reflexión. Pero a la Iglesia, como realidad teándrica, es decir, en cuanto es la concreción del plan del Padre, de la obra redentora del Hijo y de la presencia y acción del Espíritu Santo; a la Iglesia como pleroma de la Trinidad, en la que se manifiesta el genuino rostro de Dios a los hombres y su salvación. La Iglesia viene a ser la realidad primigenia querida por el Padre: el Cristo total, como 'ser' que participa el misterio mismo de Dios Trino, lo significa y lo comunica" (N. SilanES, "La Iglesia de la Trinidad"..., 118-119). 
ascensión a los cielos, sino que sigue presente, a través de su Espíritu, en la Iglesia. Todo esto gracias a que la realidad creada, y de forma particular, los hombres, son capaces de mediar la gracia de Dios. Dios se ha comprometido con la creación y la ha hecho signo e instrumento de su salvación. Es en la misma creación en donde nos encontramos con el único Absoluto. No hemos de renunciar a la creación, sino que hemos de servirnos de ella.

Sin embargo, estos actos centrales de la vida de la Iglesia que hacen presente a Cristo están también siempre marcados -en un sentido ahora negativo- por la finitud humana, de modo que la salvación no se identifica sin más con esos actos. Pero ellos son ciertamente aptos para actualizar la plenitud del amor salvador de Dios en Jesucristo, aunque de modo imperfecto, por su figura finita, humana y pecadora. La Iglesia hace presente la salvación de Jesucristo totum, sed non totaliter.

Todo esto es lo que el Vat II ha querido afirmar cuando ha declarado que Cristo constituyó a su Iglesia como sacramento universal de salvación (LG 48). En efecto, en el núcleo de la relación del hombre con Dios está el elemento histórico y social, de modo que esa relación tiene un elemento perceptible, histórico y concreto en el cual y a través del cual se realiza la definitiva autocomunicación de Dios al hombre en Cristo, y la respuesta del hombre a Dios. Por lo tanto, hay que decir que la Iglesia pertenece a la historia de la salvación, no solo como una organización religiosa útil cualesquiera, "sino como la concreción y mediación categoriales de la salvación gratuita" (35) realizada definitivamente en Cristo y el Espíritu Santo. Y eso es lo que entendemos por Iglesia en el sentido más profundo: la comunidad que "parte de Cristo y llega a mí con la exigencia y pretensión de ser la representación de Cristo en la historia perdurante de la salvación, que está acuñada por Cristo" (36).

\section{LA IGLESIA COMO SACRAMENTO DE SALVACIÓN. DESCRIPCIÓN DE LA SACRAMENTALIDAD DE LA IGLESIA}

En primer lugar, describamos brevemente esta sacramentalidad de la Iglesia. El tema, además de ser central en la eclesiología del Vat II, refiere a un elemento que distingue de manera especial a la eclesiología católica. Dos frases son claves en la Constitución Lumen gentium: "La Iglesia es en Cristo como un sacramento o signo e instrumento de la unión íntima con Dios y de la unidad de todo el género humano" (1); y "(Cristo) al resucitar de entre los muertos, envió su Espíritu de vida a sus discípulos y por medio de él (Espíritu) constituyó a su Cuerpo, la Iglesia, como

(35) K. RAHNER, Curso fundamental..., 398.

(36) K. Rahner, Curso fundamental..., 404. Había dicho este autor: "El cristianismo es autocomunicación personal del misterio sagrado de Dios, llega a nosotros de manera que se produce en nosotros una historia real de dicha comunicación de Dios mismo, y que tal comunicación sobrenatural y trascendental de Dios está mediada forzosamente en la historia. Si existe así una historia de la salvación y una historia además que se ha desarrollado hacia su absoluto e irreversible punto cimero en la historia de Jesús, el crucificado y resucitado, en consecuencia esta concreción de la historia de la salvación como mediación y concreción de mi sobrenatural y gratuita relación trascendental con Dios ya no puede cesar, es decir, tiene que haber una Iglesia" (K. RAHNER, Curso fundamental..., 403). 
sacramento universal de salvación" (48) (37). En estos textos se ve que el Concilio ha utilizado el concepto de sacramento para expresar, tanto la relación específica de la Iglesia con Dios, como su condición de servidora de la humanidad (38). En efecto, a partir de esa condición de sacramento, de una parte, la Iglesia pertenece a Cristo ya que Él, por medio del Espíritu, la constituyó su Cuerpo; y de otra, a través de ella -como por su signo e instrumento- Dios actúa en favor de los hombres (39). Es decir, la Iglesia como sacramento, por su relación con Cristo y con los hombres, se coloca en la mediación entre Dios y los hombres. Entonces, "este concepto (de sacramento) debe expresar precisamente la unidad inseparable y la diversidad infranqueable entre la Iglesia y la autocomunicación de Dios en Jesucristo y en el Espíritu Santo" (40).

Ahora bien, la definición conciliar quiere salir al paso de dos tentaciones. En primer lugar, como ya hemos dicho, nos previene de pensar en la salvación como separada de la Iglesia, como si ella fuera un simple indicador de una salvación que pudiera encontrarse en otro lugar. La Iglesia es la presencia actuante de Jesucristo a través del Espíritu (41). Pero también nos previene de pensar la Iglesia de una manera triunfalista y centrada en sí misma. En efecto, la Iglesia no es fin en sí misma "ni orienta simplemente hacia sí la búsqueda humana" (42), sino que está ordenada al reino de Dios. Es principio y germen del reino, está toda orientada hacia el reino. Está llamada a ser signo trasparente de gracia y de comunión en la historia, para lo cual debe renovarse constantemente (43).

(37) Cf. además LG 9: Dios reunió al grupo de los que creen en Jesús y lo reconocen el autor de la salvación y el principio de la unidad y de la paz, y fundó la Iglesia para que sea para todos y cada uno el sacramento visible de esta unidad que nos salva; LG 59: Dios no quiso manifestar solemnemente el misterio (Sacramentum) de la salvación humana antes de enviar el Espíritu prometido por Cristo; SC 5: Del costado de Cristo dormido en la cruz nació el sacramento admirable de toda la Iglesia; SC 26: Las acciones litúrgicas no son acciones privadas, sino celebraciones de la Iglesia, que es 'sacramento de unidad', esto es, pueblo santo, congregado y ordenado bajo la dirección de los obispos; GS 42: La promoción de la unidad está ligada a la misión íntima de la Iglesia, puesto que ella es 'en Cristo como un sacramento o signo e instrumento de la unión íntima con Dios y de la unidad de todo el género humano'; GS 45: Todo el bien que el Pueblo de Dios puede aportar a la familia humana en el tiempo de su peregrinación terrena, deriva del hecho de que la Iglesia es 'sacramento universal de salvación', que manifiesta y realiza al mismo tiempo el misterio del amor de Dios al hombre; AG 1: La Iglesia, enviada por Dios a las gentes para ser 'sacramento universal de salvación', por exigencia íntima de su misma catolicidad, obedeciendo al mandato de su Fundador, se esfuerza por anunciar el Evangelio a todos los hombres; AG 5: El Señor, habiendo recibido toda potestad en el cielo y en la tierra, antes de ascender al cielo, fundó su Iglesia como sacramento de salvación y envió a los apóstoles al mundo entero, como también Él había sido enviado por el Padre.

(38) "La calificación de la Iglesia como sacramento de salvación es un precioso medio conceptual para expresar la pertenencia de la Iglesia a Jesucristo y su condición de servidora de la humanidad" (R. BlÁzQUEZ, La Iglesia del Concilio Vaticano II (Salamanca 1988), 90).

(39) Cf. M. KeHL, La Iglesia..., 72-75; R. BlÁZQueZ, La Iglesia del Concilio..., 88-97.

(40) M. KeHL, La Iglesia..., 73. Afirma J. Rigal: "La Iglesia está situada en el misterio de Dios como aquella que anuncia y actualiza en medio de los hombres el designio de Dios realizado por Jesucristo bajo el soplo del Espíritu" (Le Mystère de L'Église. Fondements théologiques et perspectives pastorales (Paris 1996), 85). Cf. ibíd., 84-86.

(41) Cf. M. KeHL, La Iglesia..., 73.

(42) M. KeHL, La Iglesia..., 73.

(43) 'La Iglesia no es sacramento más que 'en Cristo'. Ella no se percibe jamás como una realidad autónoma y subsistente en sí misma... El pueblo de los bautizados no será 'signo’ más que en la medida que se convierta a la Palabra de Dios, para dejarse transformar, Él mismo, constantemente, 
Entonces, la Iglesia como sacramento es "germen segurísimo de unidad, de esperanza y de salvación" (LG 9). Es decir, será siempre un pequeño rebaño pero portador de esperanza cierta. Habrá siempre una desproporción entre su realidad actual y la promesa futura, entre el comienzo y la consumación, entre las capacidades humanas de sus miembros y la misión de ser signo e instrumento de la salvación manifestada en Jesucristo. Pero esa desproporción no nos puede hacer olvidar que esa Iglesia es la misma y auténtica Iglesia de Cristo manifestada en Pentecostés que está camino a su plenitud (44).

También la Iglesia es sacramento del reino. Ella no es el reino, pero es germen y principio de ese reino (LG 5). "El reino de Dios ha sido acogido por ella, desde ella se anuncia, en ella entre luces y sombras se manifiesta y por medio de ella opera en la historia" (45). Iglesia y reino no se identifican pero tienen lazos indisolubles (46): La Iglesia está llamada a vivirlo, anunciarlo e instaurarlo con poder. En efecto, no hay que olvidar que la palabra sacramento en el contexto eclesiológico del Vat. II implica, además de la realidad de signo e instrumento, que "la Iglesia es también la realidad significada y causada, es decir, el reino ya presente y actuando en medio nuestro" (47).

Además la Iglesia es sacramento de Cristo muerto y resucitado (48). Esto quiere decir que ella no es simplemente la continuadora de la causa de Jesús (49). Es

por el mensaje que Él mismo transmite. Aunque se someta al Evangelio, aunque Jesús le haya prometido la asistencia del Espíritu, Él sabe que no es propietario, sino el simple depositario de un proyecto que lo interpela a Él mismo, lo purifica, y le procura la vida y la fecundidad" (J. RIGAL, L'ecclésiologie de communion. Son évolution historique et ses fondements (Paris 1997), 324.326).

(44) "Puede, pues, decirse que la Iglesia existe ya actualmente, y desde todo su primer origen, en esta unidad que hemos descrito, pero que debe crecer hasta la parusía tanto en cada uno de sus miembros como en su totalidad. Ella existe ya, ella ha sido desde el primer momento de su existencia la 'plenitud de Cristo': aquello en lo que Él mismo se perfecciona y se completa. Pero este complemento, este perfeccionamiento en nosotros, es decir, en la Iglesia, del 'Cristo total', según la expresión tan grata a San Agustín, debe proseguirse hasta que el Cristo total, que nosotros formamos ya, llegue a la plenitud de su edad o de su talla adulta, tanto en cada uno de nosotros como en todos nosotros" (L. BouYer, La Iglesia de Dios. Cuerpo de Cristo y Templo del Espíritu (Madrid 1973), 327). Cf. ibíd., 325-332.

(45) R. BlÁZQueZ, La Iglesia del Concilio..., 93.

(46) “Así pues, es una estrecha relación la que une a la Iglesia y al Reino: relación de una transición progresiva de la una al otro, que no se acabará hasta más allá de la historia. Sin embargo, ya se perfila la Iglesia en donde se habla del Reino. El Reino va tomando forma en donde la Iglesia vive profundamente su llamada. La Iglesia es ya una porción de la humanidad en la que están presentes los bienes del Espíritu del Señor, al menos como un germen, como algo que comienza" (J.-M. R. Tillard, Iglesia de Iglesias (Salamanca 1991), 67). Cf. ibíd., 64-85.

(47) B.-D. DE LA SOUjEOLE, Le sacrement de la communion. Essai d'ecclésiologie fondamentale (Paris 1998), 45.

(48) "La Iglesia en cuanto tal se reúne en el día de hoy bajo la palabra de Cristo, y en esta reunión, que es el perfeccionamiento no solamente de su obra, sino de sí mismo, de su cuerpo, se construye como templo del Espíritu. El Espíritu, en efecto, no puede tener otro templo sino un templo de piedras vivas en el que Cristo es la piedra angular y en el que nosotros somos todos llamados a formar con Cristo una sola sociedad en la ágape del Padre. Jesús nos ha revelado esta ágape en su vida y en su muerte, y su muerte, por la resurrección que ha hecho de él para nosotros no solamente 'el Señor', sino 'el Espíritu vivificante', nos la ha dado. El Espíritu en nosotros, el Espíritu del Hijo, el Espíritu de filiación que procede del Padre mismo es su fuente permanente, y la Iglesia de la nueva y eterna alianza es su realización, todavía progresiva pero ya plenamente actual" (L. BouYer, La Iglesia de Dios..., 316). Cf. ibíd., 310-316.

(49) Cf. R. BlázQUeZ, La Iglesia del Concilio..., 94. 
mucho más que eso. Precisamente, porque la Iglesia es el Cuerpo de Cristo resucitado, porque ha sido colmada de la plenitud del Espíritu Santo (50), porque Cristo está vivo y sentado a la derecha del Padre intercediendo por nosotros, es que ella es sacramento de salvación, es decir, presencia actuante y eficaz de ese mismo Cristo que en su pascua nos ha purificado del pecado y dado nueva vida en el Espíritu (51). "La sacramentalidad de la Iglesia tiene que ver con la elección de Dios, con la misión del siervo de Yahvé y con la intercesión sacerdotal a favor del mundo" (52).

Igualmente se debe decir que la Iglesia es sacramento del Espíritu. Ella, además de ser templo del Espíritu, es obra del Espíritu. "El Espíritu Santo asiste a la Iglesia, la fortalece y la anima a realizar la obra que Cristo le ha encomendado de reunir 'a toda la humanidad con todos sus bienes, bajo Cristo como Cabeza, en la unidad de su Espíritu' (LG 13)” (53). Además, aunque la Iglesia no acapara el Espíritu que sopla donde quiere, sin embargo, ha sido dotada por su fundador como instrumento de donación del Espíritu (54). Esto quiere decir que ella ha sido elegida por Dios como casa espiritual que dona el Espíritu a sus miembros a través de su condición sacramental (55). En efecto, la Iglesia, a través de la Palabra y los sacramentos, comunica el Espíritu a los hombres para hacerlos partícipes de la santidad de Dios en la comunión con su Hijo (56). Del mismo modo, significa que el Espíritu se vale de la textura institucional de la Iglesia para llevar a la misma Iglesia a la verdad total, para hacerla comunión y para capacitarla para el servicio salvífico. Estas estructuras institucionales pueden ser la palabra predicada, los sacramentos o

(50) "El Espíritu Santo, que es el Espíritu del Padre y del Hijo en la eternidad, es el Espíritu de Cristo; le pertenece desde su encarnación, pero, sobre todo, desde su resurrección, como trofeo de su victoria sobre el pecado y sobre la muerte. Lo ha merecido para su Cuerpo y, en Pentecostés, lo ha comunicado a todos sus miembros. En su resurrección, Cristo ha venido a quedar constituido en plataforma desde la que se comunica el Espíritu Santo a toda la Iglesia, de suerte que el Espíritu es el artífice del Cuerpo de Cristo y de todo su desarrollo" (N. SiLANES, "La Iglesia de la Trinidad"..., 341).

(51) "Jesucristo, en una palabra, es el 'locus' en el que se desvela el ser divino en su condición de Ser -en Él- Padre para los hijos de adopción y en el que se manifiesta la condición del hombre como 'ser' en Cristo y desde Cristo, por la virtud del Espíritu, para el Padre. En Cristo se encuentran Dios y el hombre. En Cristo el Padre se da a los hombres 'in Spiritu' y en Cristo los hombres son aceptados por el Padre también 'in Spiritu'. En Cristo se concentra toda la salvación que, en definitiva, es Dios (el Padre) mismo que se autodona al hombre Jesús y, en Él, a todos los hombres" (N. Silanes, “La Iglesia de la Trinidad”..., 301-302).

(52) R. BlázQueZ, La Iglesia del Concilio..., 94.

(53) El Pneuma desvela el misterio de Cristo haciéndolo comprender en profundidad y asiste a la Iglesia en su tarea de anunciar a Cristo y transmitirlo... El Pneuma "conduce a la Iglesia a la unión consumada con su Esposo' (LG 4)” (N. Silanes, “La Iglesia de la Trinidad”..., 418).

(54) "Dios es santo de igual manera en las tres personas, pero la santidad ha sido atribuida de manera particular al Espíritu Santo... El Espíritu Santo es la santidad hypostática por su naturaleza misma. Por eso se le llama el Panhagion (Todo-Santo), porque él es la esencia de la santidad misma. Esta vida santificante nos es dada de múltiples maneras, especialmente a través de la Palabra y los sacramentos, estas dos formas del Pan de la vida (DV 21) donde el Espíritu se revela y se comunica. 'Por la fuerza del Evangelio, él (Espíritu) reúne a la Iglesia y la renueva sin cesar (LG 4)” (J. RigAL, Le Mystère de L’Église..., 226). Cf. ibíd., 226-228.

(55) Cf. N. Silanes, “La Iglesia de la Trinidad”..., 403-418.

(56) "El conjunto de los teólogos atribuye al Espíritu Santo la eficacia de todos los sacramentos. Gracias a 'su' acción se cumple aquello que la Palabra anuncia. Quien recorre los ritos del bautismo, de la confirmación, del orden, de la reconciliación, o de cualquier otro rito sacramental, siempre figura una invocación al Espíritu Santo" (J. RIgAL, Le Mystère de L'Église..., 227). 
la conducción del ministerio jerárquico, que como formas históricas típicas han formalizado la enseñanza, la vida cultual y el servicio de la comunión en la Iglesia. Pero en esas autorrealizaciones y manifestaciones objetivas de la fe de la Iglesia se expresa el carácter teológico de la Iglesia: "ella es la comunidad de fe creada por Jesucristo y su Espíritu Santo y anterior a sus miembros, que acoge a estos en el bautismo y los hace participar en su vida. Justamente porque la Iglesia no nace de la voluntad asociativa de los individuos ni se funda en ella, sino que nace del llamamiento de Jesucristo y de su Espíritu Santo, hay determinados elementos institucionales y formales teológicamente legítimos de la fe común" (57). Así pues, el Espíritu, a través de esas formas institucionales y de la libertad de los carismas, guía a la Iglesia a encontrar su identidad como comunidad de Cristo resucitado al identificar su mensaje con el kerygma apostólico original formalizado -por ejemplo- en una profesión de fe común; además, integra a sus miembros y comunidades en la unidad originaria y católica (= total) de la única Iglesia universal al unificar la pluralidad de comunidades en la communio sanctorum et ecclesiarum, a partir -entre otras formas- de una estructura jerárquica y jurídica, o de la identificación en la común celebración eucarística; y, finalmente, libra a la Iglesia de tener que procurarse cada vez su propia identidad, ya que esta no nace de la subjetividad de cada grupo o época, sino que viene dada 'de lo alto' (cf. Lc 24,49) y se transmite también a partir de estas estructuras formales de vida que permiten repetir hoy la experiencia original de Pentecostés. Se expresa así socialmente la unidad diacrónica y sincrónica del único Cuerpo de Cristo realizada por el Espíritu (58).

Finalmente, la sacramentalidad de la Iglesia implica también su condición escatológica. De una parte, ella está siempre en camino y con el sello de la provisoriedad. Pero, de otra parte, como vive ya de los bienes definitivos, hay en ella una condición de definitividad incoada (59). Así pues, todo lo eclesial está abierto a la consumación y está llamado a la plenitud, lo que implicará la purificación, transformación y plenificación de lo que ya ha comenzado en esta tierra. "La Iglesia, a la que todos estamos llamados en Cristo y en la que conseguimos la santidad por la gracia de Dios, solo llegará a su perfección en la gloria del cielo" (LG 48). Lo anterior supone la condición de semper reformanda (60) que ha de acompañar a la Iglesia para ser cada vez más transparencia del misterio que la sustenta. Pero supone además una diferencia actual entre el mundo y la Iglesia, ya que el hombre, aunque no deja de pertenecer a este mundo, sin embargo, ha sido ya introducido en la ciudad nueva. "El pueblo de Dios

(57) M. KeHL, La Iglesia..., 364.

(58) Cf. M. KEHL, La Chiesa come istituzione en W. KERN - H.J. POTTMEYER - M. SECKLER (EDS.), Corso di teologia fondamentale, III: Trattato sulla Chiesa (Brescia 1990), 215-225.

(59) "Aunque la Iglesia, esta Iglesia que hemos descrito como existente ya desde Pentecostés, puede juntarnos ya en ella como en la Iglesia que tiene no solamente las promesas de la vida eterna, sino también sus 'primicias' (Rom 8,23) por medio del Espíritu, sin embargo ella, por una parte, tiene todavía que extenderse 'hasta las extremidades de la tierra' (Hech 1,8) y, por otra, cada uno de sus miembros, de los que, en todo caso, están actualmente sobre la tierra, está todavía solamente en vía hacia la perfección. De ahí una última plenitud que la Iglesia espera todavía y que no le será dada antes que venga el Reino divino, con la Parusía definitiva del Salvador" (L. BOUYER, La Iglesia de Dios..., 327). Cf. B. ForTe, La Iglesia..., 348-352.

(60) Cf. L. Bouyer, La Iglesia de Dios..., 611-616. 
vive así la tensión entre la primera y la segunda llegada del Señor, rico por el don ya recibido y tenso hacia el cumplimiento de todo lo que no se ha realizado aún de la nueva creación" (61). De ese modo la dimensión escatológica impregna toda la realidad eclesial. Ahora bien, debido a esta dimensión escatológica que impregna toda su realidad, la Iglesia es el espacio de la acción del Espíritu, don de lo alto para la salvación del mundo. En efecto, la condición sacramental es don de Dios que mira a la misión en el mundo. Y en ese sentido la condición sacramental implica tanto una cercanía de la Iglesia al mundo como don para los hombres, como también, y a la vez, una presencia del Trascendente en el mundo. La Iglesia sirve al mundo, desde dentro del mundo, y comunicándole lo trascendente al mundo.

\section{SIGNIFICADO DE LA SACRAMENTALIDAD DE LA IGLESIA}

Profundicemos ahora en el significado y las razones de esta sacramentalidad de la Iglesia. En primer lugar, hemos de decir y reconocer que el cristianismo tiene esencialmente una constitución eclesial. Efectivamente, el carácter eclesial es un elemento constitutivo de la relación del hombre con Dios. La comunidad eclesial "pertenece a la existencia del hombre como tal" (62). Esto quiere decir que, si por una parte, no podemos excluir de la esencia del hombre lo comunitario, lo social, la intercomunicación. Y si, por otra parte, lo religioso, la comunicación con Dios, pertenece a la esencia del hombre en su totalidad, como fundamento y fin del mismo hombre. Entonces, "en virtud de la esencia del hombre y de Dios, y en virtud de la esencia de la relación de ese hombre con ese Dios rectamente entendido, lo social no puede excluirse de la esencia de lo religioso" (63). Eso implica que en el núcleo de la relación del hombre con Dios está el elemento histórico y social, de modo que esa relación tiene un elemento perceptible, histórico y concreto en el cual y a través del cual se realiza la autocomunicación de Dios al hombre y la respuesta de este a Aquel. Por lo tanto -como ya hemos visto-, la Iglesia es "la concreción y mediación categoriales de la salvación gratuita" (64).

Lo anterior nos pone frente a la realidad de la encarnación del Verbo (65). En efecto, en la autocomunicación de Dios al hombre -que se ha realizado en Cristo como su momento cumbre, irrepetible, definitivo y absoluto- la realidad del amor de Dios se ha expresado en lo otro que él, en la realidad de la historia humana. El amor asume lo otro como expresión propia, como símbolo que se autointerpreta y se realiza verdaderamente en nuestro mundo (66). Por eso, Jesús es el sacramento originario de Dios trino (67), porque "el Logos de Dios mismo pone esta corporali-

(61) B. ForTe, La Iglesia..., 348.

(62) K. RAHNER, Curso fundamental..., 397.

(63) K. RAHNER, Curso fundamental..., 398.

(64) K. RAHNER, Curso fundamental..., 398.

(65) Cf. K. RAHNER, Iglesia y Sacramentos (Barcelona 1960), 15-19.

(66) Cf. M. KeHL, La Iglesia..., 74.

(67) "Para marcar esa relación de intimidad, pero también de dependencia, se dirá que Cristo es sacramento 'fundamental' de Dios, y la Iglesia sacramento 'principal' de Cristo. El teólogo luterano Eberhard Jüngel distingue el único 'sacramento fundador' (Cristo), y aquella que perma- 
dad como un trozo del mundo, creándola y aceptándola a una como su realidad, la pone, por tanto, como lo otro de sí mismo, de manera que esta materialidad lo expresa a él, al Logos mismo, y lo hace estar presente en su mundo" (68). Ireneo lo ha expresado con su famosa fórmula: "el Hijo es lo visible del Padre" (69). De ese modo, Cristo, el Logos encarnado, es el sacramento de unidad por antonomasia (70). En él los creyentes se hacen una sola cosa con el Padre y se unen entre sí mediante el Espíritu Santo que los inserta en la misión de Cristo y los hace partícipes de su unión con el Padre (71).

Ahora bien, por la donación de Dios en Jesucristo y por la acción del Espíritu Santo, el Hijo encarnado se une de una manera irrevocable a la Iglesia: ella es su Cuerpo. Por el bautismo hemos sido incorporados a Cristo y en él todos participamos de su condición de Hijo: somos hijos en el Hijo (72). En efecto, "con el envío del Espíritu, donde se produce esta autocomunicación de Dios materializada en la fe de los hombres, la Iglesia como comunión de estos fieles pasa a ser de modo análogo, derivado de Cristo pero muy deteriorado por la debilidad y la culpa humanas, el 'sacramento fundamental' de todas las actuaciones simbólicas y sacramentales de esta acción salvadora de Dios en el mundo" (73). Por nuestra participación en Cristo, a través del Espíritu, nos hacemos Iglesia-comunión; y como Iglesia-Cuerpo de Cristo nos hacemos sacramento fundamental, realidad sacramental, signo e instrumento de esa unión de los hombres con Dios y de los hombres entre sí en Cristo (74). De modo que Cristo es el sacramento originario y la Iglesia -en Cristo- es el sacramento fundamental de la salvación (75).

Esta estructura sacramental de la Iglesia ha sido descrita en un párrafo especialmente importante de la Constitución Dogmática sobre la Iglesia, del Vaticano II, al relacionar íntimamente los aspectos visibles e invisibles de la Iglesia, haciendo de

nece como 'sacramento fundado' (la Iglesia), o aún, en el mismo sentido, la Iglesia como 'sacramento análogo' que envía a su vez al 'sacramento analogante', Jesucristo. Más allá del vocabulario siempre insuficiente, lo que cuenta es la realidad. Un misterio no puede ser agotado en un único concepto. Se percibe, sin embargo, que el sacramentum no puede ser aislado del musterion que invoca primero, no una dimensión eclesiológica, sino su fuente directamente cristológica" (J. Rigal, Le Mystère de L'Église..., 85). Cf. ID., L'ecclésiologie de communion..., 319-329.

(68) K. RAHNER, Curso fundamental..., 236.

(69) ADV. HAER. IV,6,6. El texto completo afirma: "El Padre se manifestó en su Verbo hecho visible y palpable: todos vieron al Padre en el Hijo, aunque no todos creyeron en él. Pues lo invisible del Hijo es el Padre, y lo visible del Padre es el Hijo".

(70) "Sacramento originario (Ur-Sakrament) de unidad es ciertamente Jesucristo; Él y el Padre son una sola cosa (Jn 10,30); en él los creyentes son una sola cosa con el Padre" (J. WERBICK, La Chiesa. Un progetto eclesiológico per lo studio e per la prassi (Brescia 1998), 487-488).

(71) Cf. J. WERBICK, La Chiesa..., 488.

(72) Cf. N. Silanes, "La Iglesia de la Trinidad”..., 343-346.

(73) M. KEHL, La Iglesia..., 74-75.

(74) Cf. LG 1.

(75) "La Iglesia es la continuación, la permanencia actual de esta presencia real escatológica de la victoriosa voluntad gratífica de Dios, inserta definitivamente con Cristo en el mundo. La Iglesia es la presencia permanente de esa protopalabra sacramental de la gracia definitiva que es Cristo en el mundo, palabra que actúa lo dicho, al ser esto dicho en el signo. La Iglesia, como tal permanencia de Cristo en el mundo, es realmente el protosacramento, el punto de origen de los sacramentos en el sentido propio de la palabra... Considerada por parte de Cristo, la Iglesia es la permanente notificación de su propia presencia en el mundo; considerada por parte de los sacramentos, la Iglesia es el protosacramento". (K. RAHNER, Iglesia y Sacramentos..., 19-20). 
ella un todo "complejo" (76). Efectivamente, afirma LG 8: "Cristo, el único Mediador, estableció en este mundo su Iglesia santa, comunidad de fe, esperanza y amor, como un organismo visible. La mantiene así sin cesar para comunicar por medio de ella a todos la verdad y la gracia. Pero la sociedad dotada de órganos jerárquicos y el Cuerpo místico de Cristo, el grupo visible y la comunidad espiritual, la Iglesia de la tierra y la Iglesia llena de los bienes del cielo, no son dos realidades distintas. Forman más bien una realidad compleja en la que están unidos el elemento divino y el humano. Por eso, a causa de esta analogía nada despreciable, es semejante al misterio del Verbo encarnado". Esto significa que la Iglesia, como misterio de salvación, se manifiesta en la tierra en forma concreta y tangible (77). "Pero de tal manera que la visibilidad está inseparable e interiormente unida a la invisibilidad, haciendo de ella una única realidad compuesta por dos elementos inherentes el uno al otro" (78). Esta visibilidad de la Iglesia es explicada aquí en su contenido teológico a partir de los dos aspectos que venimos estudiando. Por una parte, la Iglesia se muestra semejante y dependiente del misterio de la encarnación, y por otra, la Iglesia es presentada con características sacramentales. Y esto quiere decir que, en analogía con el Verbo encarnado, la constitución jerárquica, visible y tangible de la Iglesia está al servicio de la realidad invisible de gracia y de fe que en ella se media. O sea, el Espíritu de Cristo se sirve de la Iglesia, de una comunidad de hombres y mujeres pecadores, de un organismo social, como de instrumento universal de salvación mediador de la gracia. La gracia viene mediada por la Iglesia (79). Esto implica, además, que los dos elementos -divino y humano- están en una relación tal, que constituye a lo visible como órgano de salvación, en donde no se puede comprender el elemento visible sin relación al invisible, ni el invisible sin relación al visible (80). No existe uno sin relación al otro (81). Entonces, "la Iglesia, de una parte

(76) Cf. G. Philips, La Iglesia y su misterio. Historia, texto y comentario de la Lumen Gentium, I (Barcelona 1968), 143-149; L. HöDL, "Die Kirche ist nämlich in Christus gleichsam das Sakrament...”. Eine Konzilsaussage und ihre nachkonziliare Auslegung, en W. GEERLINGS - M. SECKLER, Kirche sein. Nachkonziliare Theologie im Dienst der Kirchenreform (Für H. P. Pottmeyer) (Freiburg 1994), 163-174. Especialmente 172-173.

(77) Cuerpo místico y sociedad jerárquica no evocan exactamente lo mismo, sino que cada una expresa un aspecto particular de la misma institución fundada por Cristo. En todo caso, no se puede pertenecer a una sin pertenecer a la otra.

(78) R. POLANCO, La mediación eclesial de la salvación: Teología y Vida 42 (2001) 143.

(79) Cf. R. Polanco, La mediación eclesial de la salvación..., 143.

(80) 'Con el doble concepto 'mysterium/sacramentum', el concilio retoma el lenguaje común de los padres de la Iglesia, y al mismo tiempo, destaca esa visión jurídica y canónica de la Iglesia, centrada sobre la institución, que fue elaborada desde la Edad Media hasta el Vaticano I, pasando por Belarmino. A una eclesiología que rechaza de forma general identificar de cualquier manera que sea la Iglesia de Jesucristo con la institución visible de la Iglesia, el Vaticano II opone la visibilidad y la realidad sacramental de la Iglesia de Cristo en el mundo" (W. KASPER, Le mystère de la Sainte Église. Un rappel ecclésiologique au soir d'un "siècle de l'Église”, en M. DENEKEN, L'Église à venir. Mélanges offerts à Joseph Hoffmann (Paris 1999), 309-344, aquí, pág. 328).

(81) No se trata entonces de una continuación de la encarnación, ni una encarnación rediviva, sino del Espíritu de Cristo que se hace presente y actuante en la Iglesia. Por eso dice, con palabras bien cuidadas, una non mediocrem analogiam. En efecto, en el caso del Logos, él mismo sustenta la humanidad de Cristo, de tal manera que, a través de la humanidad, se transforma en el sacramento originario de nuestra salvación. Pero es solo una analogía porque en el caso de la Iglesia, ya no es el Logos simplemente el que se une a una humanidad concreta, sino que es el Espíritu de Cristo -Dios y hombre verdadero- el que se sirve de la Iglesia como de instrumento universal de salvación. De no comprender esto podemos caer fácilmente en un monofisismo eclesiológico. 
proviene totalmente de Cristo y permanece referida a Él, y sin embargo de otra parte, en cuanto signo e instrumento existe totalmente para el servicio del hombre y del mundo" (82).

Por otra parte, la experiencia humana aboga en favor de esta concepción sacramental de la Iglesia como algo profundamente enraizado en la misma condición humana. Efectivamente, sabemos que la personalidad humana se expresa siempre en signos y gestos corpóreos. Nuestra unidad psicosomática hace que toda forma de comunicación necesite de una expresión lingüística y corporal concreta a través de la cual el sujeto pueda darse verdaderamente a sí mismo. Así pues, el gesto no remite solo al acto comunicativo, sino que al mismo sujeto que se entrega a través de ese acto (83). Es exactamente lo que sucede en el caso del amor: el gesto amoroso no remite al amor como algo separado del que lo entrega, sino que expresa, actualiza y realiza, mediante el gesto corporal, la entrega amorosa al otro en el ámbito de nuestra experiencia (84). Y en el caso de la Iglesia, significa igualmente que Dios-amor se entrega -Él mismo- al hombre, a través del signo finito y pecador que es la Iglesia, respondiendo así a la condición corporal de la humanidad creada para la comunicación con Dios (85). En la Iglesia uno se encuentra verdaderamente -aunque mediado categorialmente- con Dios mismo.

Finalmente, el concepto de sacramento ha significado siempre para la teología católica una mediación de la gracia, pero una mediación que es a través del signo, de tal manera que "los sacramentos son causas de la gracia precisamente en cuanto signos" (86). Es decir, comunican la gracia en su calidad de signos (87). Esto significa que la realidad a la cual el signo remite, está igualmente presente en el mismo signo, de tal modo que esta misma realidad significada puede a su vez comunicarse, ella misma, a través del signo (88). Esto se aplica de una manera privilegiada al mismo Cristo (89). Efectivamente, Jesucristo -por la unión hypostática- es Dios mismo que se hace presente de modo radical a la humanidad a través de la humanidad de Jesús y de su vida testimonial del amor del Padre. En Jesús Dios ha encontrado el lugar histórico-mundano para su autocomunicación salvífica, de tal manera que el hombre Jesús es, en este sentido radical arriba expresado, el signo sacramental de la presencia de Dios en el mundo. Signo que hace presente y realiza a través de sí mismo la salvación anunciada. Y la Iglesia, como comunidad de los seguidores

(82) J. Werbick, La Chiesa..., 490. Cf. también J. RigAL, L'ecclésiologie de communion..., 318-329.

(83) "El ente espiritual se realiza (actúa) exteriorizándose; al mismo tiempo él se comunica a sí mismo en medio de las propias formas expresivas y se posee/se pone. Él es en sí mismo simbólico y hecho para la comunicación simbólica” (J. WERBICK, La Chiesa..., 493).

(84) Cf. M. KeHL, La Iglesia..., 73-74.

(85) "Si el hombre es verdaderamente uno, esta unidad substancial de cuerpo y de alma apunta a la dignidad de la personalidad. La corporalidad, y por ella la visibilidad, no es accidental al hombre, sino esencial" (B.-D. DE LA SOUJEOLE, Le sacrement de la communion..., 170). Cf. ibíd., 169-170.

(86) K. RAHNER, Iglesia y Sacramentos..., 40.

(87) Cf. K. RAHNER, Iglesia y Sacramentos..., 37-44.

(88) Cf. J. WERBICK, La Chiesa..., 492.

(89) “Jesucristo es la 'visibilidad' y la 'tangibilidad' del volverse salvífico de Dios al hombre perdido, su 'símbolo originario'. Tal volverse de Dios, sin embargo, deviene visible y tangible en y con Jesucristo por el hecho que Él lo testimonió, se dejó conquistar por esa misma visibilidad y tangibilidad, y la demostró mediante una vida auténticamente humana procedente del Espíritu de Dios" (J. WERBICK, La Chiesa..., 494). 
de Cristo que han sido elegidos por Dios y asumidos en su misterio pascual, y precisamente por eso, y como presencia perdurante y escatológica de Cristo, hace presente a Cristo y a Dios mismo en su condición de Salvador que obra aquello que expresa, mientras lo expresa a través del signo de su humanidad y de la Iglesia. La Iglesia, a través de su propia realidad simbólica, y en cuanto símbolo, hace eficazmente presente al mundo la salvación de Dios y a Dios mismo. Lo mismo se podrá decir ahora para cada uno de los sacramentos como acciones en las cuales, y a través de las cuales, se hace presente el mismo Cristo en su acción salvadora a favor de la humanidad (90).

\section{ACERCA DE LA NECESIDAD DE LA IGLESIA}

Por último, la sacramentalidad de la Iglesia implica también su necesidad (91). Pero ¿cómo entender esa necesidad de la Iglesia de una manera adecuada? (92). Según lo ya dicho, en primer lugar, en el sentido que la Iglesia es objetivación de la presencia de Cristo en el mundo, que muestra siempre la vocación más profunda del hombre, en cuanto muestra el misterio pascual de Cristo como el absoluto salir de sí mismo para ir al encuentro del otro (cf. GS 22; AG 8). Y en ese sentido podemos afirmar que orienta la conciencia de todo hombre y mujer. Efectivamente, en rigor, no basta simplemente con seguir la propia conciencia, sino que esta debe orientarse en la dirección correcta que es el encuentro con el prójimo, que a la vez es presencia de Dios. Ahí se comprende la necesidad de la Iglesia como presencia viva de Cristo en medio de los pueblos, que orienta al hombre sobre su más profunda vocación de vivir del amor y de la fe que buscan salir de sí mismo para ir al encuentro de Dios en el prójimo (93). Ella es y debe ser cada vez más signo luminoso de la presencia de Cristo en el mundo. Pero es necesaria para la salvación también en cuanto es siempre un instrumento eficaz que está haciendo presente la salvación a todo el mundo, principalmente a través de la eucaristía, que es "re-presentación" del sacrificio reconciliador de Cristo. Justamente, por medio de la liturgia que ella celebra "se ejerce la obra de nuestra redención" (SC 2) ya que Cristo asocia siempre consigo a la obra de la salvación a la Iglesia, su esposa amadísima, obrando ella misma la función sacerdotal de Jesucristo por la que, mediante signos sensibles, se significa y se realiza, según el modo propio de cada uno, la santificación de todos los hombres (SC 7). Esta necesidad de la Iglesia supone e implica, en realidad, que ella tiene su esencia en ser referencia a Cristo, y por eso está llamada a purificar siempre su

(90) Cf. J. WeRBICK, La Chiesa..., 493-497.

(91) "El santo Sínodo..., basado en la Sagrada Escritura y en la Tradición, enseña que esta Iglesia peregrina es necesaria para la salvación. Cristo, en efecto, es el único Mediador y camino de salvación que se nos hace presente en su Cuerpo, en la Iglesia. Él, al inculcar con palabras, bien explícitas, la necesidad de la fe y del bautismo (cf. Mc 16,16; Jn 3,5), confirmó al mismo tiempo la necesidad de la Iglesia, en la que entran los hombres por el bautismo como por una puerta" (LG 14).

(92) Para lo que sigue, cf. R. Polanco, La mediación eclesial de la salvación..., 145-149.

(93) Cf. J. RAtzinger, El nuevo Pueblo de Dios. Esquemas para una Eclesiología (Barcelona 1972), 391-399. 
rostro para que en ella brille cada vez mejor la luz del mismo Cristo. Implica, además, que la Iglesia está llamada a convocar a todos los pueblos a Cristo, para que todos puedan gozar más plenamente de su presencia y de su gracia y se vean liberados de sus pecados e iluminados por la vida y obra de Cristo (94). El bien es por esencia difusivo de sí mismo, y la Iglesia, colmada de estos bienes de la salvación, anhela con amor poder derramarlos a toda la humanidad.

Ahora bien, esto no significa que el resto de la humanidad que no conoce a Cristo quede marginada de la salvación, sino por el contrario, significa precisamente la profunda vinculación de todos los hombres, de diversas maneras, a la única Iglesia o familia de Dios. En efecto, las fronteras de la Iglesia son sin límites. El núcleo de la humanidad es Cristo que expande su luz a todos los pueblos a través de su sacramento que es la Iglesia. De ese modo, la Iglesia se expande en diversos círculos concéntricos con Cristo en la entraña. Así, al centro se encuentran los plenamente incorporados a la Iglesia por la gracia y por los tres elementos visibles de la unidad católica: la profesión de fe, los sacramentos y las estructuras jerárquicas. Luego se encuentran los que reconocen a Cristo y han recibido el bautismo. A todos ellos se les llama Iglesias o comunidades eclesiales y pertenecen al pueblo de Dios. A continuación, en otro círculo se encuentran todos los hombres que siguen el camino de amor y de apertura al prójimo en la humildad de saberse necesitados de otros, entre los cuales destacan los miembros de las grandes religiones monoteístas. Todos ellos están ordenados al pueblo de Dios ya que pertenecen a la humanidad que ha sido salvada por Cristo y que está llamada a vivir de él (95). Justamente, hemos afirmado ya que el Espíritu Santo ofrece a todos la posibilidad de que, de un modo conocido solo por Dios, se asocien al misterio pascual de Cristo (GS 22). Y asociarse al misterio pascual es vincularse a la Iglesia y recibir, a través de ella, la gracia de la salvación. En efecto, sabemos que toda la humanidad, por la encarnación y la cruz de Cristo, ha quedado vinculada a su Señor a través de caminos conocidos solo por Dios (96). Pero toda vinculación con Cristo es además vinculación con su cuerpo y por lo tanto con la Iglesia. Toda gracia tiene vínculos antropológicos y comunitarios que nacen del ser comunitario de la humanidad y del aspecto comunitario de la salvación. Todo hombre y mujer que se salva, lo hace injertándose en Cristo, y por lo tanto, vinculándose de alguna manera con su pueblo. Ciertamente, no existe salvación aislada, sino solamente en la integración al Pueblo de Dios. El objeto de la salvación es el Pueblo y cada hombre se salva

(94) "Nadie se libera del pecado por sí mismo y por sus propias fuerzas ni se eleva sobre sí mismo; nadie se libera completamente de su debilidad, o de su soledad, o de su esclavitud. Todos necesitan a Cristo, modelo, maestro, libertador, salvador, vivificador. Realmente en la historia humana, incluso en la temporal, el Evangelio ha sido fermento de libertad y progreso y sigue ofreciéndose como fermento de fraternidad, de unidad y de paz. Por consiguiente, no sin razón, Cristo es celebrado por los fieles como 'Esperanza de las naciones y Salvador'” (AG 8).

(95) Sin embargo, en estos diversos círculos concéntricos se encuentra también entremezclada la realidad del pecado de cada hombre, que en definitiva es lo que aleja de Dios. Pero esa realidad permanecerá hasta que sea purificada definitivamente en la eternidad. Cf. Mt 13,47-50

(96) Afirma GS 22: “El que es 'imagen de Dios invisible' (Col 1,15) es el hombre perfecto que restituyó a los hijos de Adán la semejanza divina, deformada desde el primer pecado. En Él la naturaleza humana ha sido asumida, no absorbida; por eso mismo, también en nosotros ha sido elevada a una dignidad sublime. Pues Él mismo, el Hijo de Dios, con su encarnación, se ha unido, en cierto modo, con todo hombre" (destacado nuestro). 
en cuanto, mediante la fe y el amor, se hace miembro de esa comunidad de salvados. En ese sentido toda salvación es salvación por medio y en la Iglesia, en cuanto toda salvación es de Cristo y él ha vinculado -aunque de modo subordinado- su ser y su obrar a su Iglesia. Toda gracia refiere siempre a la Iglesia y vincula siempre de alguna manera con ella. Dicho en otras palabras, "el reino de Dios tiene siempre como soporte un sujeto social" (97). Este sujeto, en el sentido más amplio del término, es el entramado relacional de todas esas expresiones de justicia y paz que Dios va creando en la historia. Y eso es lo que entendemos por Iglesia en el sentido más lato: el sacramento de salvación presente y activo en todas partes, la Iglesia que une a todos los justos desde Adán hasta el fin del mundo. "A esta unidad católica del Pueblo de Dios, que prefigura y promueve la paz universal están invitados todos los hombres" (LG 13). Pero también ese sujeto social es la Iglesia institucional y católica, a la cual "le compete dentro de esta unidad la función de ser su figura socialmente más concreta y sacramental en sentido pleno" (98). Así pues, como el Espíritu Santo está ligado irrevocable e inequívocamente a sus signos sacramentales, la Iglesia católica transmite en y a través de ellos "de modo infalible la presencia del reino de Dios, que ninguna culpa humana puede destruir y ninguna provisionalidad histórica puede abolir" (99).

Sin embargo, la confesión de esta necesidad de la Iglesia no ha de considerarse como una pretensión desmedida y avasalladora de parte de nuestra fe católica. En efecto, esta no es una expresión de orden misionero, ni mucho menos una afirmación con la que haya que comenzar el diálogo ecuménico (100). Más bien, es una reflexión al interior de la Iglesia que solo quiere expresar de un modo inteligible: $1^{\circ}$ ) La grandeza y unicidad de Cristo como "Dios mismo hecho carne"; $2^{\circ}$ ) La gracia inmerecida de haber recibido en y a través de la Iglesia el don magnífico de la fe; y $3^{\circ}$ ) La convicción de que todos los hombres -ya ahora- somos hermanos e hijos de un mismo Dios y que en la eternidad no seremos más que una gran comunión o asamblea de hijos en torno al único Absoluto de nuestras vidas: Dios nuestro Padre. En el fondo, es una doxología de acción de gracias al único Dios que ha creado a todos los hombres como una gran familia de Dios (101).

\section{A MODO DE CONCLUSIÓN}

Al concluir estas líneas cerremos lo dicho con una afirmación eclesiológica básica. Uno de los elementos más característicos de una eclesiología católica -habiendo sin duda muchos otros y muy importantes- es la condición sacramental

(97) M. KeHL, Escatología..., 225.

(98) M. KeHL, Escatología..., 225-226.

(99) M. KeHL, Escatología..., 226.

(100) En todo caso, es totalmente lícito que cada religión parta su propia reflexión acerca de la revelación y salvación que propone con la convicción de la verdad y absolutez de su propia opción. Luego en la vida tendrá que probar que su pretensión es correcta, al mostrarse realmente válida y "salvadora" para cada hombre y mujer con que se encuentre.

(101) Cf. R. BERnHARDT, La pretensión de absolutez del cristianismo. Desde la Ilustración hasta la teología pluralista de la religión (Bilbao 2000), 316-319. 
de la Iglesia, como sacramento fundamental y en dependencia del sacramento originario que es Cristo, el único mediador entre Dios y los hombres. Ello hace de la Iglesia instrumento eficaz de la salvación escatológica traída por Cristo y presencia del reino anunciado e instaurado con su pascua. Esto significa que, por una parte, la Iglesia no es fin en sí misma sino que servicio del reino anunciado por Jesús, pero por otra, que ella es necesaria para la salvación de la humanidad, en cuanto es signo e instrumento de la comunión de los hombres con Dios y de los hombres entre sí, y en cuanto es germen e inicio del reino de Dios en la tierra. Ahora bien, esta comprensión de la Iglesia como sacramento implica una visión positiva de la creación en cuanto capaz de Dios y capaz de comunicar a Dios. En otras palabras, esto implica aceptar que la realidad creada, y los hombres en particular, pueden ser, en cuanto signo y también como instrumento, mediación de la gracia. Pero implica también que la "concreción" de la revelación y la Iglesia tienen para nosotros un significado positivo de vital importancia. En efecto, la finitud de la Iglesia -que nace de la finitud del encarnado- muestra a un Dios que se compromete verdaderamente con nuestra finitud, la asume como suya, la salva y la hace definitivamente lugar de salvación. Así, no debemos pensar que Dios nos pide que debamos renunciar a la finitud humana para salvarnos, algo así como renunciar a la creación. Nunca podemos renunciar a nuestra condición humana finita para salvarnos. Por el contrario, es en ella misma que encontramos la salvación traída por el Universale concretissimum: el Verbo hecho carne. Dios asume lo finito y lo hace instrumento de salvación en Cristo y -subordinadamente a él- en la Iglesia. Tras todo eso se encuentra también una determinada antropología teológica que ve al hombre, aunque pecador, como radicalmente capaz - por la gracia de Dios- de hacer presente a Dios en el mundo. Por eso, si entre las diversas confesiones cristianas se encuentran diferencias en las respectivas eclesiologías, tal vez estas radiquen más profundamente en diferencias a la hora de mirar las respectivas antropologías y teologías de la creación, y el modo en que se concibe la gracia y su mediación salvífica.

\section{RESUMEN}

El presente artículo es una reflexión acerca de la universalidad de la salvación en el cristianismo. Comienza definiendo la salvación como comunión de los hombres con Dios y de los hombres entre sí. A continuación, se refiere a Cristo como el único mediador entre Dios y los hombres, porque es Dios mismo hecho hombre, plenitud insuperable de la revelación. Esta salvación, por sus características de definitividad y absolutez, llega a ser escatológica y universal. Por otra parte, si bien la humanidad entera ha quedado transformada (=divinizada) por la venida de Cristo, al mismo tiempo, está toda entera llamada a acoger consciente y libremente esta salvación universal. Es el reino de Dios que ya ha irrumpido en la tierra. Luego, el artículo trata del papel de la Iglesia en esta salvación universal: a partir de la encarnación, que ha hecho a lo concreto camino de salvación, la Iglesia ha quedado constituida como sacramento, es decir, como signo e instrumento universal de salvación. Ella es la presencia de Cristo en la historia perdurante de la salvación. Ella, aunque es un pequeño rebaño, al mismo tiempo es germen segurísimo de salvación, ya que ella es, a la vez, sacramento del reino de Dios, sacramento de Cristo muerto y resucitado, sacramento del Espíritu, y realidad escatológica. Posteriormente, el autor reflexiona acerca del hecho de la sacramentalidad de la Iglesia: Io eclesial pertenece a la esencia de la relación del hombre con Dios, y lo simbólico-sacramental 
pertenece a la esencia de la comunicación humana. Por eso, el Verbo, en la encarnación, ha asumido la realidad humana y se ha hecho el sacramento del Padre; y la Iglesia ha devenido el sacramento de Cristo. Dios mismo se da, como tal, en el signo finito y pecador que es la Iglesia. El artículo termina con el tema de la necesidad de la Iglesia. Como sacramento de Cristo, la Iglesia es necesaria para la salvación en cuanto objetivación de la voluntad de Dios, para seguimiento de los hombres; y como instrumento de la gracia, que intercede por todos. A ella se vinculan todos los hombres de diversos modos. El autor concluye afirmando que la realidad de la Iglesia muestra que Dios asume lo finito y lo hace lugar e instrumento de salvación para los hombres.

\section{ABSTRACT}

The present article is a reflection about the universality of the salvation in the Christianity. It begins defining the salvation as men's communion with God and among men, with the meaning of plenitude for mankind. Then, it refers to Christ as the only mediator between God and mankind, because it is God himself incarnated as a man, insuperable plenitude of the revelation. This salvation, because of its characteristics of definite and absolute, becomes eschatological and universal. On the other hand, if the whole mankind has been transformed (=sanctified) for the coming of Christ, it is called at the same time to receive conscious and freely this universal salvation. It is the God's kingdom that has broken into earth. Then, the article studies the role of the Church in this universal salvation: as of incarnation, that has done the concrete way of salvation, the Church has established as sacrament, that means, the universal sign and instrument of salvation. It is the presence of Christ in the everlasting history of salvation. The Church, although is a little flock, at the same time it is the safe germ of salvation, because it is, at the same time, sacrament of God's kingdom, sacrament of Christ dead and resurrected, sacrament of Holy Spirit and eschatological reality. Afterwards, the author reflects on the fact of the sacramental characteristic of the Church: the "ecclesial" (ie. the formal and established organization) belongs to the essence of the relation of man with God, and the symbolic-sacramental belongs to the essence of human communication. That is the reason, the Word, in the incarnation, has assumed the human reality and has become the Father's sacraments, and the Church has come about the sacrament of Christ. God himself gives Himself as Such, in the finite sign and sinner that the Church is. The article finishes with the topic of necessity of the Church. As sacrament of Christ, the Church is necessary to the salvation as soon as objectivization of the will of God, for the following of men, and as instrument of the grace, that mediates for everybody. All men are linked to the Church in different ways. The author concludes affirming that the reality of the Church shows that God assumes the finite and makes it place and instrument of mankind's salvation. 